\title{
NEPOTISME DALAM PERSPEKTIF HADIS: Suatu Kajian Hadis Mauwḍ̂̀'î
}

\author{
Muhammad Sabir \\ UIN Alauddin Makassar, Jl. Sultan Alauddin 63 Makassar \\ e-mail: sabirid@yahoo.com
}

\begin{abstract}
This article deals with nepotism in the hadith perpective. Based on the takhrîj al-ahâdith related to nepotism, their sub-theme, their number of mukharrij and their number of hadith can be classified in detail as follows: the ahâtith on nepotism in Shạhîh al-Bukhârî are 3 mutûn al-hadîth; in Shhahîh Muslim are 2 mutûn al-hadith; in Sunan al-Turmûdhî is 1 matn hadîth; in Sunan al-Nasâ'î is 1 matn hadith; in Musnad Ahmad are 2 mutûn al-hadith and in Mustadrak al-Hâkim are 2 mutûn alhadith. Based on these findings, the number of hadith on nepotism are 11 mutûn al-hadîth and those ahâdith are found in the six-hadith references. However, of all the ahâdith found, none of them permitted to commit nepotism.

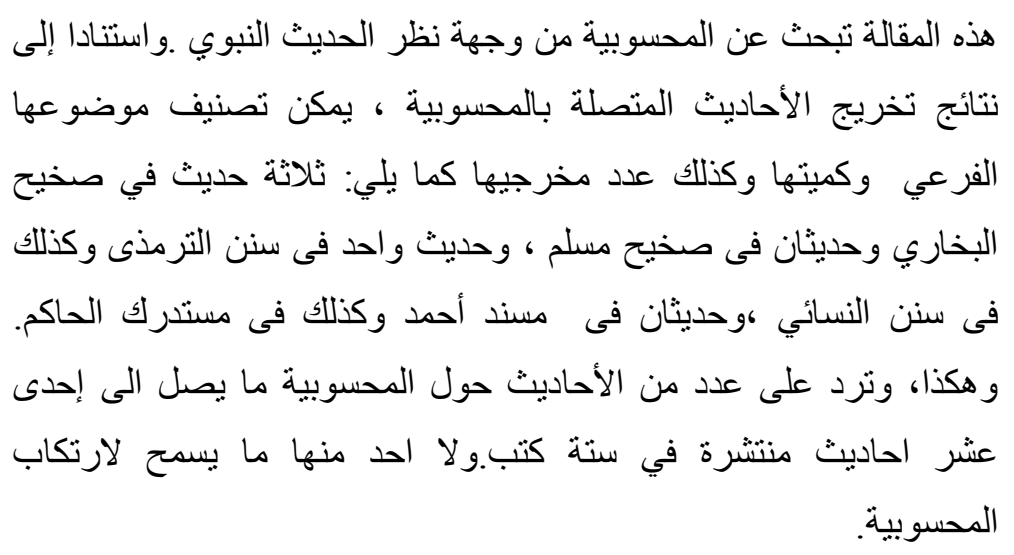

Kata Kunci: nepotisme, takhrij hadis, syarah hadis 


\section{PENDAHULUAN}

Persoalan nepotisme pada akhir-akhir ini mendapatkan sorotan yang sangat tajam baik di media massa maupun elektronik. Ia menjadi aktual karena masalah nepotisme merupakan persoalan moral dan budaya yang tumbuh dan berkembang di hampir semua sistem birokrasi suatu lembaga, baik sosial, ekonomi, maupun politik.

Term nepotisme seringkali digandengkan dengan term korupsi dan kolusi karena berada dalam satu nafas, yakni ketiganya melanggar kaidah kejujuran, melanggar hukum yang berlaku, menurunkan kewibawaan negara dan pemerintah, juga mengakibatkan high cost economy yang menaikkan harga produk dan menurunkan daya saing (Klitgaard,2001:xiii), semua demi keuntungan untuk memperkaya diri pribadi dan atau keluarga. Akibatnya, timbul kesenjangan ekonomi dan sosial antara golongan kaya raya dan berkuasa di level atas, dan golongan wong cilik yang sehari-hari harus bekerja keras untuk mempertahankan hidup yang layak di level bawah.

Pada aspek normatif, jelas bahwa nepotisme diharamkan oleh agama (Q.S 4:29-30; Q.S 5:2). Larangan ini tentu beralasan yakni karena dipandang melanggar hukum, tidak bermoral, berlaku aniaya dalam arti merugikan pihak lain. Dapat dikemukakan pula bahwa tujuan penetapan hukum dalam Islam, termasuk larangan nepotisme, adalah untuk memelihara kemaslahatan manusia sekaligus menghindari mafsadat (Al-Daraynî,1978:28; Abû Zahrah,1985:366).

Dari uraian di atas, maka yang menjadi masalah pokok dalam tulisan ini adalah bagaimana nepotisme dalam perspektif hadis nabi saw. Untuk mengelaborasi lebih jauh pokok masalah ini, dapat dikemukakan sub-sub masalah, yaitu bagaimana pengertian nepotisme; bagaimana takhrij dan syarah hadis tentang nepotisme.

\section{PENGERTIAN NEPOTISME}

Dalam Kamus Besar Bahasa Indonesia (Depdikbud,2000:613) disebutkan bahwa nepotisme adalah kecenderungan untuk mengutamakan (menguntungkan) sanak saudara sendiri, terutama dalam jabatan, pangkat di lingkungan pemerintah; tindakan memilih kerabat atau sanak saudara sendiri untuk memegang pemerintahan: para pemimpin banyak melakukan korups, menyalahgunakan kekuasaan, dan cenderung ke arah nepotisme. 
Menurut Schoorl (1980:175), nepotisme adalah praktek seorang pegawai negeri yang mengangkat seseorang atau lebih dari keluarga (dekat)-nya menjadi pegawai Pemerintah atau memberi perlakuan yang istimewa kepada mereka dengan maksud untuk menjunjung nama keluarga, untuk menambah penghasilan keluarga atau untuk membantu menegakkan suatu organisasi politik, padahal ia seharusnya mengabdi kepada kepentingan umum.

Dari pendapat di atas, dapat dipahami bahwa nepotisme adalah tindakan memanfaatkan jabatan atau kedudukan untuk mendapatkan keuntungan, baik material maupun prestise pribadi atau keluarga atau kelompok dengan jalan melanggar ketentuan-ketentuan yang ada. Nepotisme tidak dapat dipisahkan dengan korupsi dan kolusi karena ketiga tindakan ini sangat erat kaitannya antara satu dengan yang lain. Karena itu, Schoorl memandang nepotisme sebagai bagian dari tindakan korupsi.

Namun demikian, ketiga istilah tersebut dalam tataran defenitif masih dapat dibedakan satu sama lain. Korupsi lebih berkonotasi penyalahgunaan kepentingan umum (mas $\square$ allih 'ammah) termasuk di dalamnya negara, pemerintah, masyarakat atau organisasi untuk kepentingan pribadi atau sekelompok orang. Sedangkan kolusi cenderung berkonotasi penyimpangan kedudukan, wewenang dan jabatan untuk mewujudkan maksud dan kepentingan sekelompok orang yang berkepentingan sama. Adapun nepotisme berkonotasi pada pengutamaan kerabat dekat dalam pengangkatan suatu kedudukan dan jabatan dalam pemerintah atau BUMN.

\section{TAKHRIJ HADIS-HADIS NEPOTISME DAN KLASIFIKASINYA}

\section{Takhrij Hadis Nepotisme}

Kata takhrîj secara etimologi adalah kumpulan dua perkara yang saling berlawanan dalam suatu masalah (al-Tahan,1978:9). Selain itu kata takhrîj juga diartikan; (1) al-istinbât (mengeluarkan dari sumbernya); (2) al-tadrîb (melatih atau penghabisan); (3) al-tawjih (menerangkan) (Ibnu Mandhûr,1968:249). Jadi takhrîj al-hadith dapat berarti mengeluarkan hadis. Maksudnya segala yang ada kaitannya dengan apa yang diteliti, dan ditelusuri secara keseluruhan hingga tuntas dan menjadi jelas, dapat juga berarti mengeluarkan dan 
meriwayatkan hadis dari beberapa kitab (Al-Hâdî,1994:2).

Sedangkan secara terminologi menurut ulama hadis, takhrîj alhadîth memiliki beberapa pengertian sebagai berikut:

- menunjukkan asal usul hadis dan mengemukakan sumbernya dari berbagai kitab hadis yang disusun oleh para mukharrijnya langsung, yaitu para periwayat yang juga sebagai penghimpun bagi hadis yang mereka riwayatkan.

- mengemukakan hadis berdasarkan sumbernya, yaitu kitab-kitab hadis, yang di dalamnya disertakan metode periwayatan dan sanadnya, serta diterangkan keadaan para periwayat dan kualitas hadisnya.

- mengemukakan hadis kepada orang banyak dengan menyebutkan para periwayatnya dalam sanad yang telah menyampaikan hadis itu dengan metode periwayatan yang mereka tempuh.

- mengungkapkan hadis yang telah dikemukakan oleh para guru hadis atau berbagai kitab yang disusun berdasarkan riwayatnya sendiri, para gurunya atau orang lain, dengan menerangkan siapa periwayatnya dari para penyusun kitab yang dijadikan sumber pengambilan.

- menunjukkan letak asal hadis pada sumbernya yang asli, yaitu dalam berbagai kitab, yang di dalamnya dikemukakan hadis itu secara lengkap dengan sanadnya masing-masing, kemudian untuk kepentingan penelitian, dijelaskan kualitas hadis yang bersangkutan (Ismail,1992:42; 'Abd al-Hâdî,1994:3; Rahman,1991:18; Husnan,1993:97; al-Tahan,1978:9-14; Jumantoro, 1997:244).

Dalam kaitannya dengan itu, dan untuk mencari hadis-hadis tentang nepotisme, penulis melakukan takhrîj al-hadith melalui alat bantu Mu'jam al-Mufahras li Alfâz al-Hadîth al-Nabawiyah.

Takhrîj hadis tentang nepotisme dilakukan dengan menggunakan lafal عمل/أثرة dan. Melalui lafal Mum (Wensinc,1969.Juz I:14) memberikan petunjuk sebagai berikut:

$$
\begin{aligned}
& \text {... ستلقون بعدي أثرة فاصبروا ... }
\end{aligned}
$$

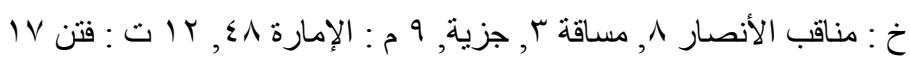

Sedangkan melalui lafal عمل, dalam Mu'jam (Wensinc, 1969. Juz IV:379 \& 446) ditemukan petunjuk sebagai berikut: 


$$
\begin{aligned}
& \text { ألا تستعملني كما إستعملت فلانا .... }
\end{aligned}
$$

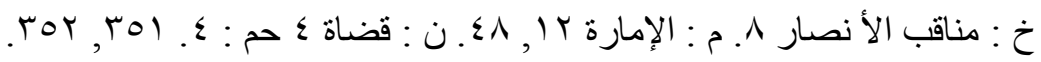

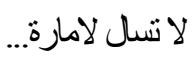

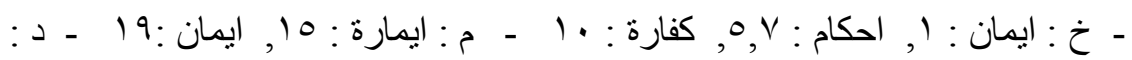

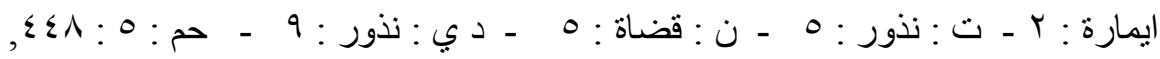

$$
\begin{aligned}
& \text { Tr }
\end{aligned}
$$

Berdasarkan petunjuk Mu'jam hadis di atas maka dapat diketahui bahwa hadis tentang nepotisme terdapat dalam kitab-kitab rujukan hadis sebagai berikut:

- Sḥahîh al-Bukhârî, Kitâb Munâqib al-Anșâr, bab 7; kitab Masâqah bab 3; Kitâb Jâziyah bab 9.

- Ș̣̣ahîh Muslim, Kitâb Imârah nomor hadis ke- 12 dan ke-48.

- Sunan al-Turmudhî, Kitâb al-Fitn, bab 17.

- Sunan al-Nasâ'î, Kitâb al-Qaḍâ', bab 4.

- Musnad Ahmad bin Hanbâl, juz 4, halaman 251 dan 252.

Selanjutnya, takhrij untuk hadis-hadis tentang nepotisme ini, jika ditelusuri melalui alat bantu berupa Jâmi' al-Saghîr karya AlSuyût $\square \hat{1}$, juga ditemukan petunjuk bahwa hadis-hadis tentang nepotisme terdapat pula dalam Mustadrak al-Hâkim.

\section{Klasifikasi Hadis}

Berdasarkan penelusuran dari hasil takhrij hadis-hadis yang terkait dengan nepotisme, dapat diklasifikasi sub temanya, jumlah mukharrij-nya dan jumlah hadisnya dengan perincian sebagai berikut :

Hadis tentang nepotisme dalam Ș̣̣ahîh al-Bukhârî 3 matan hadis; dalam Shhahîh Muslim, 2 matan hadis; dalam Sunan alTurmûdhî 1 matan hadis; dalam Sunan al-Nasâ'î, 1 matan hadis; dalam Musnad Ahmad 2 matan hadis dan dalam Mustadrak al-Hâkim, 2 matan hadis. Dengan demikian, jumlah hadis tentang nepotisme sebanyak 11 matan hadis dan hadis-hadis tersebut terdapat dalam 6 kitab rujukan hadis.

Berdasarkan klasifikasi tersebut, dapat diketahui bahwa hadishadis tentang nepotisme bervariasi matannya dalam 6 kitab hadis. Hadis-hadis tentang nepotisme yang telah di-takhrij dan diklasifikasi 
tersebut, tampaknya memiliki redaksi matan yang berbeda antara satu dengan yang lainnya. Dengan demikian, dapat dikatakan bahwa hadishadis tentang nepotisme diriwayatkan secara maknawi. Sebagian hadis-hadis tentang nepotisme tersebut dikutip dalam bahasan selanjutnya untuk dianalisis secara tematik (sharh al-ḥadith bi almawḍ̂u'î).

\section{SYARAH HADIS NEPOTISME}

Penyelenggaraan kekuasaan dengan sikap nepotisme telah diprediksi oleh nabi saw., sebagaimana dalam beberapa teks hadis. Berikut ini, akan dikutip dua hadis yang terkait dengan masalah tersebut. Dua hadis yang dimaksud adalah riwayat al-Bukhârî dan alTurmûdhî sebagai berikut:

- Hadis riwayat al-Bukhârî (1987: no. 3508):

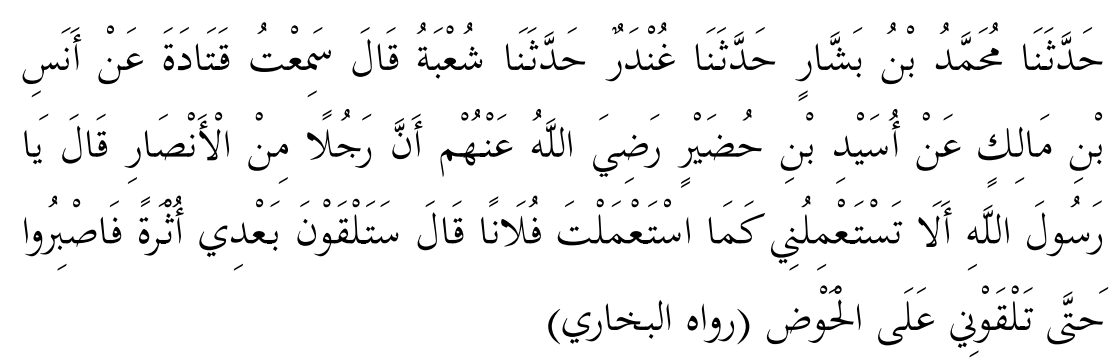

Telah bercerita kepadaku Muhammad bin Bashshar telah bercerita kepada kami Ghundar, telah bercerita kepada kami Shu'bah berkata, "Muhammad bin Bashshar menceritakan kepada kami, berkata: Gundar menceritakan kepada kami, berkata: Shu'bah menceritakan kepada kami, berkata: Saya mendengar Qatâdah, berkata:dari Anas bin Mâlik, berkata: dari Usaid bin Hudayr yang kesemuanya periwayat ini (semoga) diridai Allah swt. berkata: bahwa seorang laki-laki dari kaum Anșâr berkata: Ya Rasulullah, tidaklah engkau angkat si Fulan? Rasul menjawab: kalian akan menjumpai sepeninggalku tindakan mengutamakan kepentingan sendiri (sikap nepotisme), maka bersabarlah kalian sampai bertemu denganku di telaga alkauthar (di hari kiamat)." 
- Hadis riwayat al-Turmûdhî (1988; no. 2115):

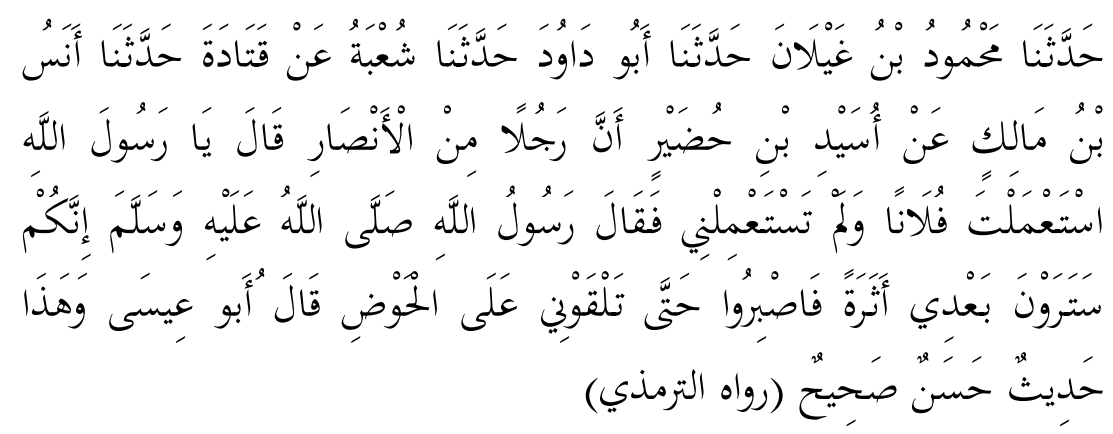

"Telah bercerita kepada kami Mah $\square$ mûd bin Ghaylânî berkata: Abû Dâwud menceritakan kepada kami, berkata: Qatâdah menceritakan kepada kami, berkata: Anas bin Mâlik dari Usayd bin $H \square u d \square$ ayir berkata bahwa seorang laki-laki dari kaum Anșâr berkata: Ya Rasulullah, tidakkah engkau angkat si fulan? Rasul menjawab: kalian akan menjumpai sepeninggalku tindakan mengutamakan kepentingan sendiri (sikap nepotisme), maka bersabarlah kalian sampai bertemu denganku di telaga alkauthar (di hari kiamat).

Dua hadis yang dikutip di atas, memiliki redaksi matan yang berbeda. Hadis pertama di pertengahan matannya menggunakan lafal sedangkan hadis yang kedua menggunakan lafal ستلقون . Secara tekstual kedua lafal ini memiliki kesamaan makna.

Ungkapan ألانسـتعملنى merupakan pernyataan sekaligus pertanyaan Usayd bin Huduayr terhadap rasul, yang berharap agar dia dijadikan sebagai 'âmil (pegawai) yang mengurusi zakat, ataukah diangkat sebagai gubernur pada suatu daerah (al-Athqalânî, t.th.:118). Keinginan Usayd tersebut didasari kenyataan bahwasanya rasul telah mengangkat orang-orang tertentu untuk tugas tersebut seperti halnya 'Amr bin Ash sebagaimana yang dimaksudkan dari ungkapan استعملت فلانا

Terhadap permintaan Usayd tersebut, secara arif rasul menanggapinya dengan ungkapan انكم ستلقون بعد اثرة. Jawaban rasul tersebut dimaksudkan untuk menolak permintaan Usayd itu secara halus berdasarkan pertimbangan tertentu beliau. Tampaknya permintaan tersebut dikemukakan Usayd di hadapan orang banyak, terbukti dengan jawaban yang diberikan Rasul menggunakan frase 
dan فاصسبروا. Dengan demikian, pernyataan tersebut tidak hanya ditujukan khusus kepada Usayd, tetapi bersifat umum.

Menurut al-Nawâwî (1994:546), perintah untuk bersabar yang tercantum dalam hadis di atas memberi kesan untuk menahan diri dari keluh kesah. Hal ini penting karena ketika seseorang diserahi amanah atau tanggungjawab, harus tetap istiqamah pada aturan atau normanorma ajaran agama. Di samping itu, anjuran bersabar dalam hadis di atas akan mencegah seseorang untuk bersikap nepotisme, karena kecenderungan sikap nepotisme tersebut lahir dari kurangnya kesabaran sehingga selalu berpikir pendek dan sesaat (alSuyûtî,2006:135).

Nabi saw. secara arif dan sadar ingin menanamkan kesadaran kepada sahabatnya bahwa ada masanya nanti setelah beliau telah tiada, terjadi praktek nepotisme yang dilakukan oleh para pejabat yang diserahi amanah dan tanggung jawab terhadapnya.

Mengenai kata أثرة berasal dari akar kata اثر yang berarti bekas dan dapat pula berarti kecenderungan. Dalam konteks hadis tersebut, menurut Abû Ubayd, أثرة berarti mementingkan diri sendiri dalam hal pembagian al-fay' (Al-Mubârakfûrî,1979:427). Pengertian ini dikuatkan oleh al-Kirmânî yang mengartikan أنثرة dengan sikap penguasa yang selalu mengutamakan dirinya dan keluarganya dalam mendapatkan keuntungan duniawi. Dewasa ini kecenderungan sikap seperti itu identik dengan nepotisme.

Menghadapi kenyataan hidup seperti itu secara bijak nabi saw. menyeru agar bersabar. Muh $\square$ ammad Abû Bakr al-Râzî (1991:323) mengartikan sabar dengan menahan diri (nafsu) dari keluh kesah. Sedangkan Wajdi (1979:105) mendefinisikan dengan sikap meninggalkan keluhan atau pengaduan selain kepada Allah swt.

Sikap nepotisme harus - untuk tidak mengatakan wajibdihindari dengan cara menguatkan komitmen untuk berprilaku honest dan lurus. Di sisi lain, harus ada kesadaran bahwa segala aktivitas manusia senantiasa mendapat pengawasan dari Allah. Juga penanaman nilai-nilai moralitas yang mengacu pada rasa keadilan dan persamaan perlakuan di hadapan hukum. Kesemuanya ini penting disosialisasikan kepada masyarakat dan Pemerintah sebagai upaya pencegahan terhadap praktek nepotisme. 
Berdasarkan keterangan di atas, dapat dipahami bahwa nepotisme sesuai dengan pengertiannya, bertujuan "mengawetkan" atau dalam batas-batas tertentu "memaksakan" kehendak dan kepentingan untuk "merajai" kekuasaan (politik) dan kekuasaan ekonomi (bisnis), sehingga salah satu dampaknya adalah praktek monopoli yang didominasi oleh keluarga atau orang-orang dekat tertentu. Sehingga nabi saw. menyarankan agar menghadapi suasana demikian, haruslah disertai kesabaran.

Berdasarkan hasil penelusuran penulis dalam berbagai kitab rujukan, dapat dikemukakan bahwa hadis-hadis tentang nepotisme, ditemukan riwayat mengenai sabab wurûd-nya, yaitu ketika ada ketentuan dari Allah swt. (melalui Alquran) mengenai al-fay' (harta rampasan perang), maka Rasulullah membagi al-fay' tersebut seusai Perang Hunain pada orang-orang mu'allaf, dan orang-orang Anșâr tidak mendapat pembagian al-fay'. Padahal mereka (kaum Anșâr) beranggapan akan memperoleh (al-fay') sebagaimana yang diperoleh orang-orang selainnya. Lalu Rasulullah berpidato dan berkata: Wahai orang-orang Anșâr kamu dahulu dalam keadaan tersesat, lalu karena aku maka Allah memberi kalian petunjuk; kalian juga dahulu saling bercerai-berai, lalu karena aku maka Allah menjadikan kalian bersatu; kalian juga dahulu hidup dalam keadaan papa, lalu karena aku maka Allah menjadikan berkecukupan. Setiap Rasul mengucapkan sesuatu, mereka (kaum Anșâr) menyatakan: Allah dan rasul-Nya lebih mengetahui. Lebih lanjut Rasulullah saw. bersabda: apakah kalian merelakan manusia pergi dengan membawa kambingnya atau dombanya dan kamu (juga rela) pergi bersama Rasulullah saw. ke suatu tempat, dan sekiranya bukan karena hijrah maka kalian tidak menjadi orang-orang Anșâr; sekiranya pula manusia melewati sebuah lembah atau bangsa, maka akan melalui lembahnya Anșâr dan bangsa Anșâr yang menggunakan pakaian dalam untuk selimut. Lalu nabi saw. menyabdakan hadis ستلقون بعدى أثرة فاصبرو حتى تلقونى اللحوضز (AlSuyûtîi,1984:226).

Untuk melengkapi kedua hadis tentang nepotisme di atas, dapat dikemukakan pula bahwa hadis tentang nepotisme juga dapat ditemukan masing-masing dari: 
- Riwayat Muslim (1980:474), dalam Ṣahîh Muslim dalam Kitâb alImârah (terdapat dua hadis)

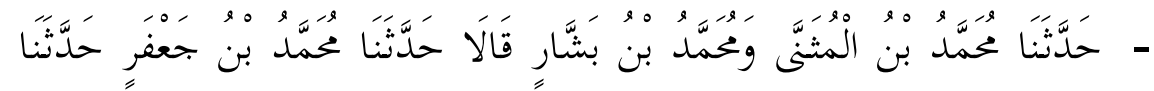

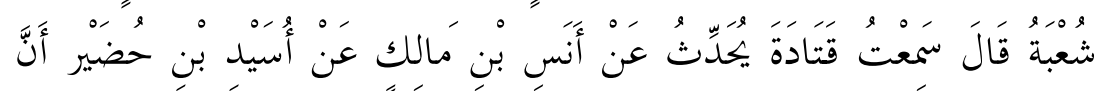

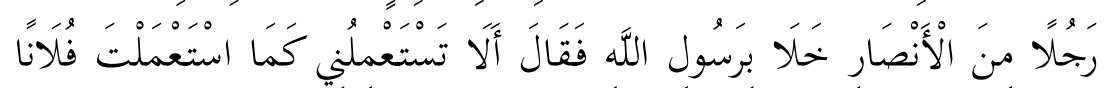

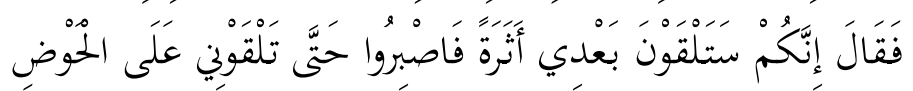

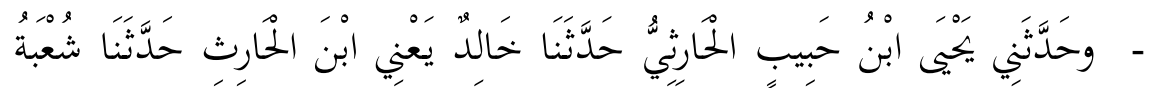

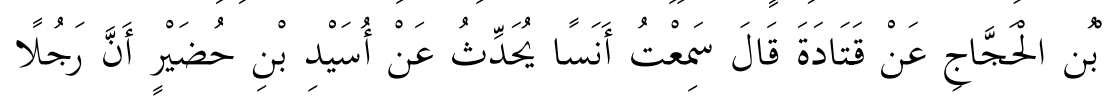

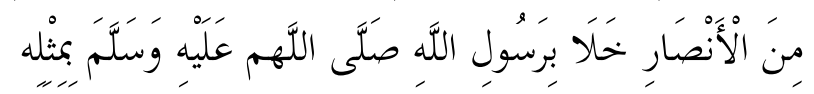

- Riwayat al-Nasâ'î (t.th.:225) dalam Kitâb Adab al-Qad $\square \hat{a}$ '

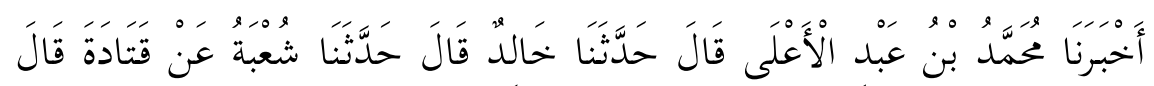

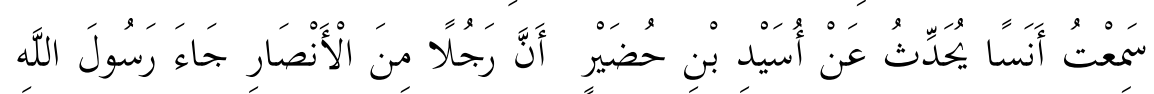

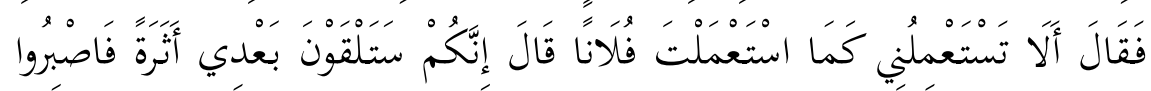

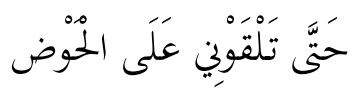

- Riwayat $\mathrm{Ah} \square \operatorname{mad}($ t.th.:351-352) dalam Musnad al-Kûfiyyin (dua jalur sanad)

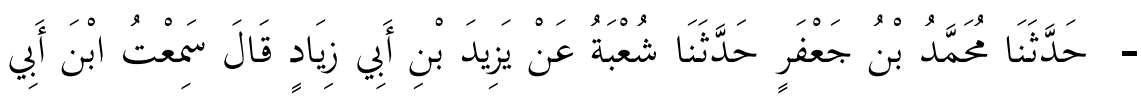

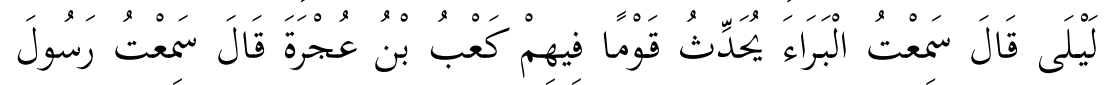

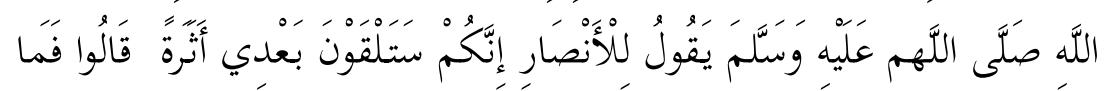

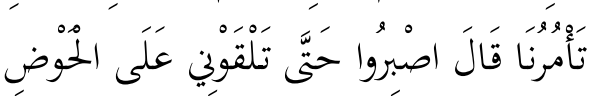




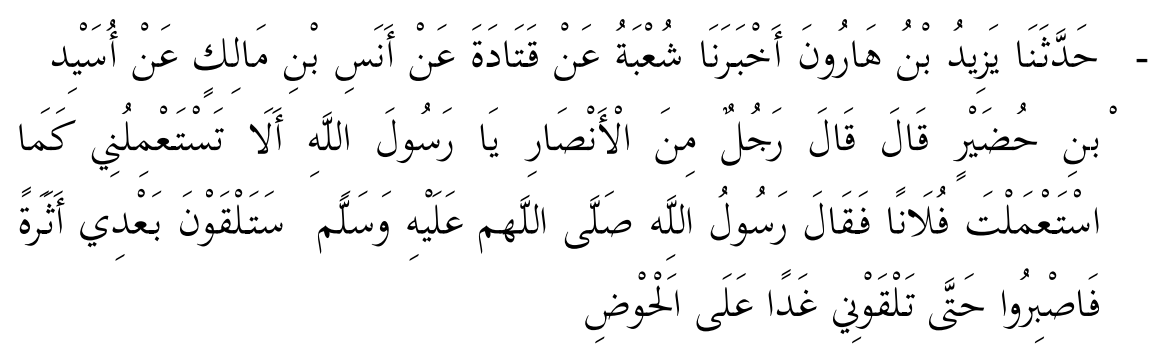

\section{PENUTUP}

Setelah menganalisis berbagai uraian sebelumnya, dapat ditarik kesimpulan bahwa pertama, nepotisme adalah perbuatan yang melanggar hukum, norma, dan aturan agama. Oleh karena itu, perbuatan nepotisme harus dihindari; kedua, tujuan penetapan hukum dalam Islam, termasuk larangan nepotisme adalah untuk memelihara kemaslahatan sekaligus menghindari mafsadat. Ada lima unsur pokok yang harus dipelihara dan diwujudkan (الضروريات الخمسة) dalam rangka menegakkan tujuan hukum Islam, yaitu memelihara agama, jiwa, akal, keturunan, dan harta; dan ketiga, seruan nabi untuk bersabar menyikapi sikap nepotisme penguasa, dimaksudkan agar sendi-sendi kehidupan umat senantiasa tetap terpelihara dengan baik. Patut diyakini bahwa nabi di sini secara sadar dapat melihat berbagai kemungkinan negatif apabila sikap nepotisme tersebut disikapi pula secara keras dan frontal.

Berdasarkan uraian kesimpulan di atas, implikasi tulisan ini diharapkan dapat menjadi daya dorong bagi pelaksana pemerintahan. Oleh karena itu, disarankan kepada segenap pihak, khususnya kepada para pejabat negara dan masyarakat agar senantiasa menghindarkan diri dari sikap dan praktek-praktek nepotisme, karena perilaku seperti ini, bertentangan dengan ajaran agama.

\section{DAFTAR PUSTAKA}

'Abd al-Hâdî, Abû Muhammad Mahdi bin 'Abd al-Qadîr. Metode Takhrij Hadis. 1994. Terjemahan oleh Sayyid Aqil Husain al-Munawwar dan Ahmad Rifqi Mukhtar. Cet I. Semarang: Dina Utama

Abû Zahrah, Muhammad. 1985. Usûl al-Fiqh. Mesir: Dâr al-Fikr al-'Arabî. al-Athqalânî, ibn Ḥajar. T.th. Fatḥ al-Bârî bi Sharḥ SSahîh al-Bukhârî, Juz VII dan XV. T.tp.: Dâr al-Fikr wa Maktabah al-Salâfiyah.

al-Bukhârî, Muhammad ibn Ismâ'îl Abû 'Abd Allâh, Sahịh al-Bukhârî. 1987M-1407. Jilid. 1. Cet . III. Beirut: Dâr Ibn Kathîr al-Yamâmah

al-Darâynî, Fâth. 1975. Al-Manhaj al-Uṣ̂lliyah fî al-Ijtihâd bi Ra'y fî alTashrî'. Damaskus: Dâr al-Kitâb al-Hadîth. 
Departemen Pendidikan dan Kebudayaan. 2000. Kamus Besar Bahasa Indonesia. Jakarta: Balai Pustaka.

Husnan, Ahmad. 1993. Kajian Hadis Metode Takhrij. Cet. II. Jakarta: Pustaka al-Kautsar.

Ibn Hanbâl, Muḥammad Ahmad. T.th. Musnad Ahmmad. Juz IV. Beirut: Maktabah Islâmiyah li al-Ṭaba'ah wa al-Nashr.

Ibn Mandhûr, Abû al-Faḍl Jamâl al-Dîn Muhammad Ibn Mukram. 1396 H/1968 M. Lisân al- 'Arab. Juz II. Beirut: Dãr al-Sadr.

Ismail, M. Syuhudi. 1992. Metodologi Penelitian Hadis Nabi. Cet. II. Jakarta: Bulan Bintang.

Jumantoro, Totok. 1997. Kamus Ilmu Hadis. Cet. I. Jakarta: Bumi Aksara.

Klitgaard, Robert. 2001. Controlling Corruption. Terjemahan oleh Hermoyo dengan judul Membasmi Korupsi. Cet. II. Edisi ke-2. Jakarta Yayasan Obor Indonesia.

al-Mubârakfûrî, Abû al-Ûlâ Muhammad bin 'Abd al-Rahmân. 1979. Muqaddimah Tuhfah al-Ahwâz bi Sharḥ Jâmi' al-Turmûdhî. Juz VI. Beirut. Dâr al-Fikr.

al-Nasâ'î, Abû 'Abd al-Raḥmân Aḥmad bin Su'ayb. T.th. Sunan alNasâ'î. Juz VI. Beirut: Dâr al-Ma'ârif.

al-Nawâwî, 1994. Șahịh Muslim bi Sharḥ al-Nawawî. Beirut: Dâr al-Kutub al-'Ilmiyyah.

al-Qushayrî, Abû Ḥusayn Muslim bin Ḥajjâj. 1980. Șậ̣ḥ Muslim. Juz II. Beirut: Dâr al-Kutub al-'Ilmiyah.

Rahman, Fatchur. 1991. Ikhtisar Musthalahhul Hadits. Cet. VII. Bandung: PT. Al-Ma'arif.

al-Râzî, Muhammad Abû Bakr. 1991. Mukhtâr al-Ṣiḥhah. Beirut: Dâr alFikr.

al-Suyûtị̂, Jalâl al-Dîn 'Abd al-Rahmân. 1967. Jâmi' al-Ṣaghîr fî̀ Ahâdîth alBashîr al-Nadhîr. Jilid I. Kairo: Dâr al-Kutub al-'Arabî.

al-Suyûtî. 1984. Asbâb al-Wurûd al-Hadîth. Cet. I. Beirut: Dâr al-Maktab al-'Ilmiyah.

Suyuti, Machmud. 2006. Syarah Hadis-Hadis Kontroversial. Cet. I. Makassar: YAPMA.

al-Tahan, Mahhmûd. 1398 M./1978 M. Uṣ̂l at-Takhrîj wa Dirâsât alAsânîd. Halb: Matba'ah al-'Arabiyyah.

al-Turmûdhî, Abû 'Isâ Muhammad ibn 'Isâ. 1988. Sunan al-Tirmudhî alJâmi' al-Ṣahîh. Jilid III. Dârul al-Fikr.

Wajdi, Muhammad Farid. 1979. Dâ'irah al-Ma'ârif al-Qarn al-'Ishrîn, Jilid V. Beirut: Dâr al-Fikr.

Wensinck, A. J. 1969. Al-Mu'jam al-Mufahras li Alfầz al-Ḥadith alNabawiyah. Juz IV. Leiden: E.J. Brill. 